\title{
La etno-etnohistória de los procesos de ocupación y afirmación territorial de los Tucano occidentales del río Putumayo: narrativas siona y fuentes documentales del período extractivista 1860-1930
}

Ethno-ethnohistory of the processes of territorial occupation and affirmation of the Western Tucanoans of the Putumayo River: Siona narratives and historical documents from the extractivist period 1860-1930

Camilo Mongua Calderón*

* Universidad de la Amazonia - Florencia, Caquetá, Colombia camiloo12@gmail.com https://orcid.org/0000-0001-6292-5744

Esther Jean Langdon ${ }^{\star *}$

** Universidade Federal de Santa Catarina - Florianópolis, SC, Brasil Pesquisadora de CNPq jean.langdon@ufsc.br https://orcid.org/0000-0002-5883-3000 


\title{
Resumen
}

Este artículo explora la consciencia histórica de los procesos de ocupación y afirmación territorial en la región fronteriza entre Ecuador y Colombia, una región ocupada tradicionalmente por los grupos de Tucano occidentales. A partir de diferentes modos de investigación antropológica e histórica, examinamos y correlacionamos la etno-etnohistoria de los Siona sobre la época extractivista de quina y caucho con los documentos escritos de los archivos estatales y religiosos. Los documentos escritos revelan la preocupación del gobierno colombiano por la presencia, defensa y control estatal del territorio. Las narrativas orales de los Siona tratan de la ocupación de su territorio ancestral como lugar de pertenencia y relaciones de intercambio y conflicto entre los asentimientos indígenas. En lugar de relatar los conflictos con los nuevos invasores de su territorio ancestral, las narrativas Siona de este período recuerdan las epidemias y otras desgracias que afligieron a los asentamientos ubicados a lo largo del río Putumayo, y se inscriben, en la geografía las memorias de los eventos críticos en que los curacas son los principales protagonistas.

Palabras clave: territorialidad; río Putumayo; etnohistoria; narrativa.

\begin{abstract}
The article explores the historical consciousness of the processes of territorial occupation and affirmation in the borderlands between Ecuador and Colombia, a region occupied traditionally by Western Tucanoan groups. Based on historical and anthropological investigations, we examine and correlate written documents with the ethno-ethnohistory of the Siona indigenous people of the period of quinine and rubber extraction. The written documents reveal the Colombian government's concern for establishing presence, defense and state control of its territory. Siona oral narratives are about occupation of their ancestral lands as a place of belonging and of relations of exchange and conflict between the indigenous settlements. Rather than recounting the conflicts with the territorial invaders, Siona narratives of this period recall the epidemics and other misfortunes that afflicted their settlements along the Putumayo River, and inscribe in the geography the memories of critical events evoking relations between humans and non-humans in which shamans are main protagonists.
\end{abstract}

Keywords: territoriality; Putumayo River; ethnohistory; narrative. 
Este artículo explora la "etno-etnohistoria" de los procesos de ocupación y afirmación territorial en la región fronteriza entre Ecuador y Colombia entre 1845-1930, una región que ha sido ocupada tradicionalmente por los grupos de Tucano occidentales. Hoy la mayor parte de los Tucano occidentales viven en el río Putumayo y se identifican como Siona, o como Gantëya bain, la gente del río de Caña Brava. A partir de diferentes modos de investigación antropológica (Langdon, 2014, en prensa) e histórica (Mongua Calderón, 2018, en prensa), examinamos y correlacionamos las narrativas de los Siona, sobre el período de economía extractivista de la quina y del caucho en el medio Putumayo, con los documentos escritos de archivos estatales y religiosos que tratan del mismo período. Estamos aquí preocupados por la historia indígena, o sea, la etno-etnohistoria definida por Turner (1988), como un modo de conciencia que informa el presente y que podría contribuir para la defensa del territorio ancestral en que los indígenas Siona se encuentran ocupando en la actualidad. Diferente a lo que puede ser esperado en las narrativas de este período - relatos de los abusos de los patrones blancos o de los conflictos con los padres capuchinos que llegaron para para frenar el avance de los patrones peruanos, las memorias de este período recuerdan las epidemias y otras desgracias, que afligieron sus asentamientos a lo largo del río Putumayo, siendo protagonizadas por los líderes chamánicos (cacique-curacas).

La estructura socio-política de los Siona en esta época no consistía tanto en unidades de parentesco organizadas como clanes como se ha descrito para los Tucano orientales (Hugh-Jones, 1979), sino que consistía más bien en grupos de familias aliadas bajo el liderazgo de un chaman-líder (cacique-curaca) y agrupados en asentamientos dispersos a lo largo del río Putumayo. Los diferentes grupos se identificaron con estos asentamientos y circularon alrededor de estos a causa de los eventos críticos tales como epidemias y/o muertes de los curacas. Las narrativas cuentan de estos eventos en los asentamientos a través de una perspectiva "cosmopolítica" (Albert, 2002), inscribiendo en la geografía y el ambiente memorias que evocan las relaciones entre humanos y no-humanos, relaciones en que los curacas son sus principales protagonistas.

Las narrativas también representan cómo los Siona se identifican con su territorialidad, si consideramos que son memorias del esfuerzo colectivo de un grupo social para ocupar, usar e identificarse con un lugar específico y su entorno biofísico, convirtiéndolo así en su "territorialidad" o homeland (Little, 2002, p. 3). 
La territorialidad de un grupo es un producto histórico de procesos sociales y políticos. Emerge en contextos específicos, en que el territorio es defendido o reafirmado y se transforma a través del tiempo, dependiendo de las presiones históricas ejercidas sobre él. El territorio del Estado colombiano se afirmó mediante la defensa y el control de una región específica, mapeada en un plano geográfico unidimensional. En contraste, la territorialidad para los Siona es una "conducta territorial", es decir, que se expresa a través del concepto de "cosmografía". Según Little (2002, p. 4, traducción de los autores), la cosmografía incluye "conocimiento ambiental, ideologías e identidades, creadas colectivamente y situadas históricamente, que un grupo social utiliza para establecer y mantener su territorio". Esta visión incluye el régimen de propiedad, la memoria colectiva de ocupación, las formas de defensa, los vínculos emocionales y el uso social del territorio.

La historia de la región andino-amazónica de los siglos XIX y XX ha sido abordada de manera marginal en las historiografías nacionales de Ecuador, Colombia y Perú. Estas historias nacionales se han centrado en el estudio de los ejes de las ciudades andinas y costeras, dejando de lado los espacios amazónicos, a lo que Barclay (2001) denominó el "olvido de una historia", es decir, de la región andino-amazónica al interior de este campo disciplinar. En comparación a los historiadores, en gran medida han sido los antropólogos quienes se han aproximado al pasado indígena a través de la etnohistoria, al cuestionar la interpretación que había situado a los indígenas amazónicos como sociedades estáticas, congeladas en el tiempo e integradas en el siglo XX por los Estados-nación y las fuerzas del mercado (Taylor, 1994). Algunos académicos han contribuido para la construcción de la historia del impacto del comercio de quina y caucho sobre los habitantes indígenas (Pineda Camacho, 2000; Taussig, 2002; Wasserstrom, 2014). Las investigaciones de Augusto Gómez López $(2006,2010)$ son los trabajos más importantes para la historia del Putumayo. Este antropólogo e historiador centró sus estudios en la incorporación

1 Para Barclay las divisiones disciplinares entre la historia y la antropología ayudaron a profundizar los imaginarios de la Amazonía como lugar para la civilización y de las sociedades indígenas congeladas en el tiempo. Estas divisiones entre historia y antropología termino por reproducir estos imaginarios en el estudio de las "tierras bajas", los antropólogos encargados de estudiar los grupos selváticos "congelados" y "fosilizados" en el tiempo y los historiadores los núcleos urbanos de los Andes y la Costa en el proceso de formación del estado (Barclay, 2001; Taylor, 1994). 
de los grupos indígenas, el impacto de las misiones tanto coloniales como republicanas, el papel de la misión capuchina en el siglo XX, el proceso de colonización y la perdida territorial desde una perspectiva de historia social. A pesar de estas contribuciones, la historia según los grupos indígenas aún permanece en un estado de desconocimiento.

Respecto a la construcción de la historia indígena, adoptamos la perspectiva de la construcción narrativa de la historia característica de la erudición norteamericana (Basso, 1995; Hill, 1988). Nuestro enfoque no concierne a la distinción binaria entre mito e historia (Lévi-Strauss, 1966) que ha motivado el análisis estructural de los mitos independientemente del contexto. Como Haden White (1981) afirma en su artículo, el discurso histórico moderno y la narrativa se refieren al significado moral: una demanda de secuencias de eventos reales evaluadas en su importancia como elementos de un drama moral. La narrativa histórica es una "representación de eventos reales que surgen del deseo de que los eventos muestren coherencia, integridad, plenitud y cierre de una imagen de vida que es y solo puede ser, imaginaria" (White, 1981, p. 23, traducción de los autores). Hill (1988, p. 2) editó un influyente volumen examinando la construcción de la historia entre los pueblos amazónicos, buscando comprender la agencia sociocultural de aquellos que han sido sometidos a una dominación estructural extra-local. De acuerdo con este volumen, y el que posteriormente editó Albert y Ramos (2002), analizamos las narrativas Siona como un régimen de historicidad que inscribe su perspectiva en los acontecimientos históricos durante el período entre 1870 y 1930 . Como Turner señala en las observaciones finales del volumen de Hill, la narrativa representa un modo indígena de conciencia que expresa su interpretación de la historia con nuestra sociedad. Es una "etno-etnohistoria" que disloca el enfoque en la lógica del mito para la práctica, contexto y performance con el entendimiento que los géneros narrativos se refieren a los sentidos propositivos y modos de orientar las formas sociales, políticas, rituales y otros modos de acción histórica (Turner, 1988, p. 241).

Además de representar una colaboración entre una antropóloga y un historiador que han realizado investigaciones en la región, este artículo está orientado principalmente hacia los intereses expresados por los Siona, quienes se encuentran en un período de revitalización cultural y ritual en la defensa de su territorio tradicional. La devolución de los textos narrativos grabados en la década de 1970 (Langdon, 2018a) comenzó en 2012 a través de la organización 
de talleres sobre su idioma y la distribución de grabaciones digitalizadas acompañadas de parlantes USB alimentados por batería. En respuesta a estas actividades de colaboración, en 2019 los líderes Siona de la comunidad de Buenavista solicitaron la historia de su origen en el Putumayo. En 2020, ambos autores participaron en un taller que examinó las narrativas históricas en un intento de mapear los eventos narrados según las ubicaciones de sus asentamientos a lo largo del río Putumayo. Además de presentar la historia según los ancianos, tal como se contó en la década de 1970, este artículo tiene el propósito de colaborar con los esfuerzos de los Siona para construir su etnohistoria y legitimar sus derechos al territorio ancestral.

\section{Período Franciscano en el Medio Putumayo}

Antes de la llegada de los españoles en el siglo XVI, los Tucano occidentales ocupaban un gran territorio que abarcaba los ríos Putumayo, Aguarico y Napo de Colombia, Ecuador y Perú. Los archivos coloniales indican que vivían en malocas de unas 30 a 70 personas dispersas por toda la región. Los nombres de los grupos identificados que pertenecieron a esta sub-familia lingüística varían en los documentos históricos y también los estimativos poblacionales. La evidencia arqueológica reciente de otras regiones del Amazonas sugiere que las poblaciones de los Tucano occidentales anteriores a la conquista eran mucho más grandes de lo que se pensaba anteriormente (Wasserstrom, 2014).

Los primeros intentos de ocupación europea de la región comenzaron en el siglo XVI con la extracción de oro fluvial y la llegada de los misioneros jesuitas y franciscanos que intentaron reunir a los grupos indígenas en "reducciones" en torno a la figura de la misión. En el río Putumayo, el control franciscano de los Tucano occidentales se enfrentó con la resistencia armada y epidemias que diezmaron los asentamientos misioneros, escapando a otras localidades. Frente el aislamiento de la región selvática, las dificultades de acceso y la resistencia indígena, los franciscanos abandonaron este territorio a finales del siglo XVIII.

Durante los siglos XVII y XVIII, los franciscanos construyeron iglesias y formaron asentamientos nucleados, con una plaza central en diferentes lugares del río Putumayo, incluidos no solo San Diego y San José, sino también otros 
lugares, como Sunxi, ${ }^{2}$ Guepí, San Francisco de Amaguajes, Mamo, Concepción, Tabacuntí y Agustinillo [para una lista completa de las misiones vea Apéndice II (Langdon, 2014)]. Los Franciscanos introdujeron la parafernalia y rituales cristianos, la monogamia y vestimenta; también intentaron explotar el trabajo indígena y establecer la monogamia. Su presencia causó epidemias, disensos y rupturas entre los grupos indígenas, causando una catástrofe demográfica (Gómez López, 1998). Los documentos históricos indican que la población de Tucano occidentales en el tiempo de contacto disminuyó en un 70\%, por lo menos (Langdon, 2014, p. 43-54).

La presencia francisana y la disminución poblacional impactaron de manera significativa la organización socio-política de los Tucano occidentales del Putumayo, lo cual se puede evidenciar en varias de las narrativas que los Siona cuentan sobre las misiones de los franciscanos y las batallas chamánicas en que los curacas atacaron a los curas (Langdon, 1990). Las varias narrativas que se localizan en este período presentan una versión alternativa a la de la historia oficial sobre los hechos violentos del encuentro colonial con los europeos. Desde el primer contacto en 1562 hasta la salida de los franciscanos al final del siglo XVIII, los Siona explican la discontinuidad de las misiones como resultado del poder de sus curacas. Contrariamente a la historia oficial de este período que describen las dificultades debido a la resistencia nativa, a las epidemias y al aislamiento de la región, los Siona se reconstruyen los acontecimientos en el contexto de su esquema cosmopolítico más amplio, que otorga a sus chamanes un papel clave en la defensa de sus comunidades frente a los invasores, tanto en el combate armado, como en contra de las epidemias que los acompañaron.

Es posible especular que el papel de líder político antes de la llegada de los europeos fue sustentado a través de las relaciones de parentesco, estructurándose según divisiones de clanes patrilineales organizadas jerárquicamente, como las que se encuentran entre los Tucano orientales en el Vaupés de Colombia (Hugh-Jones, 1979). Las malocas, en base de parentesco, fueron lideradas por los hermanos mayores de la familia extensa con separación entre el papel político (líder político) y sagrado (chaman). Si se organizaron así en el Putumayo,

2 Como vamos ver, Sunxi está recordada en las narrativas Siona como ubicación de una de las batallas con los Chufi o Tetetes. 
la relocalización forzada en los centros de misiones y la gran pérdida demográfica llevó a que esta organización política se tornara inviable. Las malocas desaparecieron y la organización socio-política se reconfiguró. Las fuentes históricas del siglo XIX describen asentimientos de alianzas de familias nucleares (con o sin relaciones de parentesco) asociadas con un cacique-curaca. Varios de estos asentimientos circularon alrededor de las fundaciones de las misiones, con los cuales ellos continuaron identificándose. El liderazgo del cacique-curaca combinaba en un solo papel las funciones políticas y religiosas a través de su poder chamánico y la apropiación de las prácticas de control de los franciscanos.

\section{Período extractivista $1870-1930$}

En 1845 el Territorio del Caquetá fue creado como una jurisdicción especial perteneciente a la Provincia del Cauca de la República de la Nueva Granada y fue dividida en corregimientos para su administración. La nueva estructura jurídico-política se estructuró a partir de los asentamientos de los grupos indígenas del Putumayo (Mongua Calderón, 2020) y fueron creados los corregimientos de Sibundoy, Mocoa, Aguarico y Putumayo. El corregimiento de Putumayo fue conformado por los pueblos de San Diego de San Juan, San Diego de Putumayo, Cuembí, y Mamo (Concepción), antiguas misiones que persistían tras la salida de los franciscanos como asentimientos de los Tucano occidentales.

Con el establecimiento de estas jurisdicciones el comercio entre los andes, el piedemonte del Putumayo y la cuenca media del mismo río, fue aumentando a través de la utilización de la mano de obra indígena. En 1857 el secretario del territorio del Caquetá José María Quintero documentó las actividades económicas llevadas a cabo en los asentamientos de los corregimientos:

Los granadinos embarcan sus cargamentos en las inmediaciones donde la sacan, y de este modo viene a ser ignorada la cantidad que explotan: sin embargo, se supone que en este año saldrán unos 50 quintales, más o menos. De igual modo, y con más razón, se ignora respecto al barniz [...] La cera blanca, cera negra, zarza, vainilla, barniz, achiote preparado para manufacturas y para guisar, copal, 
catana, ungüento de María, ajengibre, flor de canela, pita, hamacas, venenos, bodoqueras, manteca de tortuga, peje [sic.] salado, carne ahumada y oro, son los artículos que forman el comercio, extrayéndolos para Neiva, Popayán, Pasto, Perú y Brasil. En cambio, de tales artículos vienen plata, sal, lienzos, zarazas, bayetas, pailas, hierro bruto, herramientas, anzuelos, abalorios, espejos, cerdos y perros de caza. (Domínguez; Gómez; Barona, 1997, p. 132).

El aumento del comercio de productos del bosque llevó a que los grupos indígenas se articularan de manera temprana al comercio, con anterioridad al boom de la explotación de la quina y el caucho (Mongua Calderón, 2020).

La extracción de quina inició en 1874 seguido por el boom del caucho que se prolongó en el medio Putumayo hasta 1930 aproximadamente. Con la extracción de caucho, la región se hizo centro de disputa internacional cuando los peruanos y otros intentaron aprovechar la mano de obra indígena a través de la esclavitud y el peonaje por deudas (Casement, 1988). Para proteger sus fronteras, el gobierno colombiano encargó a los padres capuchinos y a los caucheros colombianos para que representaran al Estado y protegieran sus fronteras (Mongua Calderón, 2018). Los grupos de Tucano occidentales se tornaron una vez más el foco de disputas y control por parte de extraños, y la organización socio-política de sus asentimientos resultó fundamental para el desarrollo de estos dos auges extractivos de quina (1874-1880) y caucho (1880-1930) (Mongua Calderón, 2020).

La expansión de la extracción de caucho en el Putumayo estuvo marcada por la migración de comerciantes del interior del país y comerciantes extranjeros de Perú y Ecuador. A pesar de que la cuenca media del Putumayo contaba con géneros de menor calidad (caucho y balata) en comparación a los ubicados en la cuenca baja del río (hevea), los comerciantes caucheros se expandieron hacia río arriba, incrementando su presencia entre los Tucano occidentales. La extracción de resina de baja calidad de caucho y balata requirió que los grupos de trabajadores se movilizaran por la selva, cortando y transportando el caucho. Los asentamientos familiares basados en alianzas con curanderos poderosos (curacas) facilitaron la recolección de caucho en esta región. Los Kofán, Siona, Macaguaje, Tetetes y grupos inganos se vieron envueltos en estas actividades, recibiendo a cambio del caucho, herramientas o mercancías, siendo endeudados sin saber lo que ganaban o que debían. Con el incremento de la demanda 
mundial de gomas los caucheros se establecieron en los pueblos de las comunidades indígenas, controlando y dislocando familias enteras.

Las informaciones sobre la participación de los Tucano occidentales en la extracción de las gomas están presentes en la documentación escrita de los archivos colombianos. La producción de información del Putumayo del siglo XIX se encuentra principalmente en los archivos que contiene la información del Territorio del Caquetá (Archivo Central del Cauca) y la misión capuchina (Archivo Histórico Diócesis Mocoa-Sibundoy; Archivo Hermanos Menores Capuchinos). Estos documentos hacen parte de los proyectos estatales de las nacientes repúblicas y de los intereses de las órdenes religiosas y la Iglesia Católica por reestablecer las misiones en las fronteras amazónicas. Sin embargo, estos dos archivos no solo revelan las pretensiones del gobierno y de la Iglesia Católica, también nos permiten interpretar a través de las fuentes documentales la historia de los grupos indígenas según estos documentos.

Las fuentes escritas utilizadas en este artículo fueron recolectadas en el trabajo de archivo de la investigación doctoral (Mongua Calderón, 2018) que rastreó la manera en que el Estado colombiano había logrado mantener sus pretensiones amazónicas a lo largo del siglo XIX. La lectura de las fuentes documentales de estos dos archivos reveló la existencia de numerosos asentamientos indígenas en la cuenca media del río Putumayo. Sin embargo, los documentos estatales poco informaban sobre los indígenas que habitaban en estos lugares. En cambio, las fuentes de la misión capuchina proporcionan un mayor detalle de estos asentamientos. Esta información que proporcionan los documentos escritos son fuentes de gran relevancia para la historia indígena y los procesos actuales de los Siona en la revitalización de sus narrativas etnohistóricas, la defensa del territorio ancestral y de sus procesos organizativos.

La diversidad del tipo de fuentes en los archivos: cartas personales, informes oficiales, memorias de excursiones apostólicas revelan un complejo universo en que se encontraban inmersos los Tucano occidentales. Por ejemplo, las cartas personales hacen parte de la correspondencia interna de los misioneros, documentos que reflejan la vida cotidiana del desarrollo de los pueblos y las misiones. Los informes de las excursiones dan cuenta de las visitas de los curas a los asentamientos, el recibimiento de los indígenas, las fiestas y la realización de bautismos y matrimonios. 


\section{Las narrativas históricas de los Siona}

Las narrativas se registraron en la década de 1970 en el resguardo de Buenavista del río Putumayo, unos 40 kilómetros abajo de Puerto Asís. En la época, la población los Tucano occidentales en el río Putumayo se estimaba entonces en alrededor de 300 personas (Wheeler, 1987, p. ix), diseminadas en caseríos pequeños a lo largo del río y sus tributarios abarcando una distancia de 250 kilómetros aproximadamente. Los residentes de Buenavista, el mayor y más importante de los caseríos, se identifican a sí mismos como Gantëya bain (Gente del río de Caña Brava).

En 1970, la tradición de performance oral era todavía una práctica importante para transmitir la historia del grupo a las generaciones más nuevas, aunque esta tradición desapareció en las décadas siguientes cuando la vida cotidiana de los Siona se transformó radicalmente debido a la producción de coca, la violencia y la extracción del petróleo. Las historias orales de los Siona se contaron y volvieron a contar continuamente en un proceso de reproducción social a través de la poética de la performance (Bauman; Briggs, 1990). El contexto tradicional para narrar sus historias, sueños y experiencias es durante las primeras horas de la mañana cuando los miembros de la familia se despertaban y sentaban para tomar yoco (Paullina yoco) y fabricar sus canastas, redes, mochilas de fibra y otros objetos. Los abuelos son reconocidos como depositarios de la memoria sobre su historia y su territorio, y los otros escuchan sus diferentes versiones y perspectivas, que circulan en diversos contextos. La comprensión de la etno-etnohistoria Siona y la construcción de su territorialidad se basa en la participación en una historia y cultura comunes, y en la familiaridad con el conjunto más amplio de textos orales.

Más de 150 narrativas fueron registradas, la mayor parte grabadas en la lengua Siona y narradas por los abuelos mayores. Otra fuente fue un joven intelectual que no sólo sabía narrar muchas de las narrativas de sus abuelos, sino además también había aprendido a escribir su idioma durante un período en que trabajó con el lingüista colombiano Manuel Casas-Manrique y, como consecuencia de su labor, registró aproximadamente 40 narrativas de los abuelos de la década de 1960.

Muchos de los textos registrados, de una forma u otra, hacían referencia a la historia que sucedió en la cuenca media del río Putumayo entre 1870 y 1930. 
Estos se interconectan y se complementan entre sí, proporcionando detalles de las memorias de su ocupación del Putumayo y sobre las relaciones entre los caseríos y sus curacas. Cada narrativa cuenta sobre episodios y personajes que, a su vez, se vinculan con otros eventos críticos, ubicaciones y actores; tomadas en conjunto, estas narrativas representan en buena medida la etno-entohistoria disponible de los Siona.

Para explorar la conciencia histórica y la manera cómo los Siona se identifican con su territorialidad, comenzaremos con una narrativa que cuenta de la llegada del primer misionero a la región y de la llegada de los Gantëya bain al río Putumayo, estableciendo el vínculo ancestral de este grupo con el territorio e introduciendo a los otros sub-grupos reconocidos también como habitantes del medio Putumayo. Posteriormente examinaremos las otras historias que informan sobre los diferentes sub-grupos y de los cacique-curacas de los caseríos en el Putumayo, así como los eventos críticos del siglo XIX y el inicio del XX. Identificamos dos temas recurrentes en las narrativas: uno que trata de los caseríos y sus curacas, evidenciando una red chamánica compuesta de relaciones de intercambio y conflicto. El segundo tema trata de las fiestas y celebraciones que marcaban la vida de los caseríos en una época cuando los Gantëya bain, liderados por sus caciques-curacas, todavía se sentían dueños de todo el medio Putumayo.

La narrativa que sigue, Wayusañë, es considerada por los Siona actuales como capaz de legitimar su presencia ancestral en el río Putumayo. Fue narrada en 1972 por Aurelio Maniguaje, un residente de Buenavista que nació alrededor de la década de 1910 y creció en las últimas décadas de la extracción del caucho (Langdon, 2018b). Al igual que los otros narradores de su edad y abuelos mayores, no solo contó los eventos presenciados en su vida, sino también, sobre eventos más antiguos que fueron transmitidos por sus padres y abuelos.

\section{Wayusañë: La ciudad ancestral}

La gente vivía en el pueblo de Wayusañë.

Era una región de sola gente, con indígenas de diferentes pueblos. ${ }^{3}$

Los niños descendieron a la pequeña quebrada y se bañaron.

3 Algunas versiones de esta narrativa nombran a los diferentes pueblos: Siona, Macaguaje, Coreguaje, Tama, Uitoto, Kofan, Ancutere, Tetete e Inganos. 
Mientras se bañaban, vino de río arriba, de una gran roca, vino una persona.

$\mathrm{Al}$ verlo, los que se estaban bañando salieron corriendo del agua.

Estaban desnudos, sin ropa, como Dios los había dejado en los primeros tiempos.

"No tengan miedo, soy tu abuelo", dijo el desconocido.

Tenía una barba muy larga.

Y los niños corrieron rápido para contarles a sus padres.

"El abuelo ha llegado; es abuelo", ellos dijeron.

Y luego llegó y los padres se reunieron para verlo.

"Soy tu abuelo", dijo.

"Que abuelo es usted?", preguntaron.

"Me llamo Amo", él dijo.

Y los padres llamaron a todas las demás personas para que vinieran a ver.

"Soy tu hermano mayor, me llaman Amo", dijo.

Estas son personas de otro grupo y sus hijos, hoy se llaman Amo y Ocoguaje.

La gente se reunió y habló.

Otros en la región no querían su presencia.

"No es de aquí, solo va engañar", dijeron.

Ellos no querían su presencia.

Pero los primeros dijeron: "Queremos al hermano mayor que ha llegado".

Otras personas se reunieron y escucharon la conversación.

En la ciudad a donde él vino, había un árbol de wayusa, de pie junto a un cedro.

Fueron dejados por Dios en los primeros tiempos.

Los curacas ${ }^{4}$ soplaron las hojas de wayusa en agua.

Los enfermos tomaron y se alentaron. ${ }^{5}$

El Amo que llegó hizo una casa grande al pie de los árboles.

Hizo la casa de Dios, una casa para rezar.

En esa casa reunió a todos los que vivían allí para dar consejo.

Entonces venían otros, gente de otros llanos llegaron.

Y cuando vieron, los otros dijeron: “No, él es solo engañándonos, es engañoso".

No querían a él.

4 rau sëсосиа - los que soplan enfermedades

5 Este es un árbol sagrado utilizado por los chamanes para sanar. En otra versión, se usa para hacer invisible a la ciudad, después de que los chamanes beben yajé y ven que los forasteros causarán el fin de los pueblos indígenas. La gente huye, dejando solo un bosque embrujado. 
Y el Amo nombró el gobernador, un cacique, un tigre (chaman), nombró un tomador del yajé.

Y el cacique viajó por todo el territorio para inspeccionar.

Y sus fiscales acompañaron a él y le cargaban.

Por un mes él andaba casa por casa, mirando a las mujeres, a los hombres;

a los que trabajaban y a los que no trabajaban,

Él miró a todos los trabajos -

A las mujeres limpiando las chagras, tejiendo ollas, a todos los trabajos.

Él mandó a ellos continuar trabajando para alimentar a los niños.

En toda la región andaba.

Salía de su casa cuando la luna estaba nueva y llegaba cuando terminaba el mes.

Era una región muy grande, una región de gente, todos los grupos vivían juntos en un pueblo.

El cura estaba viviendo allí por un tiempo y ya los otros pensaron malos.

“Él está solo engañándonos", dijeron éstos enojados.

Los primeros vivían bien, ya tejieron la ropa de algodón.

Los otros, entre ellos mismos, se mataron y se comían. No querían poner la ropa. Trabajaron la cascara de árboles con sus lanzas y rasparon los cueros de los animales.

Vestían en la ropa del monte. ${ }^{6}$

Con el tiempo, se volvieron malos.

Bebieron chicha, se pusieron bravos y levantaron sus lanzas.

Estaban muy bravos y enojados.

Rasparon muchas lanzas, y se pusieron los cueros de animales y pelearon.

Levantaron una guerra con sus lanzas, mataron a los curas y se fueron.

Los curas que sobrevivieron abandonaron el pueblo y se fueron.?

Desde esta ciudad, todos los indios se dispersaron.

Río abajo en el Caquetá se fueron los Tama y Coreguaje.

Nosotros, el pueblo Gantëya, los Siona, vinimos a este lugar, a este gran río.

6 Los Siona se consideraban cristianos a la llegada de los misioneros, y estaban orgullosos de ser civilizados, diferentes de los Airu bain, refiriendo a los aucas o incivilizados.

7 Esta es referencia a la última misión franciscana en el Putumayo, que fue abandonado en el final del siglo XVIII. 
Vimos qué buen río es el Gantëya, lleno de peces, buena caza y abundantes cosechas.

Toda la gente vio que es un buen río para vivir.

Y mientras bajaban por el Putumayo, vieron a otros.

La Gente Lanza (Hui bain) ellos se llamaban.

Ellos se llamaban los barbaros Chufi, y vivieron en el Putumayo.

Tenían piel fea, con manchas. Su piel estaba negra con caretes. ${ }^{8}$

"Estos son feos, no queremos unirnos a ellos, atraparemos su enfermedad".

Los curacas (yai bain) persiguieron y mataron a los Chufi.

Otros chamanes en el monte bebieron yajé y transformando en tigres se los comieron y así los terminaron.

Otros Gantëya bain fueron más río abajo, hasta el lugar llamado Charco de Pescados.

Y en ese lugar pelearon nuevamente con los Chufi, y los mataron con sus lanzas. Cortaron sus cabezas y las colocaron sobre lanzas atrapadas en la arena.

Ese lugar se llama Sinjogu (transportador de cabezas).

Y desde allí, los Chufi se dispersaron y huyeron a la selva.

Se escondieron en el bosque, siguieron a nuestros cazadores y robaron su caza.

Y el Siona les disparó con dardos envenenados.

Y luego persiguieron a algunos Chufi nuevamente, matándolos con lanzas mientras se bañaban en un pequeño río.

El lugar donde los mataron se llama serpiente Chufiya.

Los blancos lo llaman Masaya. ${ }^{9}$

En todo este lugar, el río Putumayo, los Gantiya bain se extendieron y ahora somos muchas personas.

Esta narrativa evoca una época cuando los Tucano occidentales vivían en paz en la ciudad de Wayusañë, una gran comunidad multiétnica liderada por un solo cacique que gobernaba un vasto territorio. La versión de Juan Yaiguaje

8 Simson (1879, p. 220) identifica el "carate" como una enfermedad de la piel común al Piojé (Siona) que aparece como manchas oscuras o negras en su forma leve o piel escamosa negra, y seca en su forma severa.

9 La narrativa de Juan Yaiguaje sobre la ciudad de Wayusa (Portela Guarín et al., 2003, p. 64-65) indica que originalmente se llamaba Quebrada el Sábalo (mahuansoya) pero que los españoles la llaman Mansoya. 
publicada en el Plan de Vida (Portela Guarín et al., 2003, p. 64-66), nombra los Siona, Oyo, Macaguajes, Kofan, Huitoto, Ancutere, Coreguaje, Tama y Inganos como habitantes de la región. Las diferentes versiones de la narrativa establecen a los Siona como los residentes legítimos del medio Putumayo. En general ubican la ciudad en la región entre Puerto Asís y Mocoa, o la asocian, como en esta versión, con las antiguas misiones franciscanas de San Diego y San José y con los Siona con sobrenombres de Amo, Yocuro y Amaguaje, ${ }^{10}$ y que hablaron bain coca (siona) con un acento diferente.

La referencia a la llegada del primer padre que proclamó ser el amo, colapsa el tiempo narrativo del siglo XVII al XIX, y mezcla, las primeras experiencias en las misiones franciscanas, con las de los hermanos menores capuchinos. El padre que llegó y anunció que era el amo, es al mismo tiempo el jesuita Rafael Ferrer que a principios del siglo XVII vivió entre los Kofán (aliados cercanos de los Siona), se hizo su amigo, habló su idioma y que luego ellos lo ahogaron (Kohn, 2002); y los padres capuchinos barbudos que llegaron a finales del siglo XIX." Según otras narrativas que los Siona cuentan sobre su historia, a la llegada de los capuchinos, ellos ya tenían conocimiento de Cristo y de Dios a través de sus curacas y del uso del yajé, y afirman que el papel de su liderazgo, el cacique-curaca, fue autorizado por Dios. Según ellos, Dios otorgó los poderes y responsabilidades de los curas a los cacique-curacas, dando a este líder la responsabilidad de defender, disciplinar y supervisar a sus comunidades, y de aconsejarles para que vivan de manera adecuada. ${ }^{12}$ Estaban orgullosos de ser civilizados y se distinguían de los Macaguaje (Airu bain, gente del monte), identificados en la narrativa como la gente que usaba ropa del monte.

10 Otras narrativas de este período también identifican a estas dos comunidades asociándolas con los Amaguajes, quienes, según los Siona y Castellví (1962, p. 34, 236) hablaban de un acento ligeramente diferente.

11 El diario de Fray Juan de Santa Gertrudis (1970) cuenta también del ahogamiento del cura en la misión de Santa Cruz de los Mamos en el río Putumayo en 1757.

12 Estos poderes implicaron no solo aspectos políticos, mas también los rituales. En los rituales chamánicos el yajé estaba servido en cálices de cerámica, recordando la misa, y los curacas realizaron ceremonias de matrimonio y también apropiaron aspectos de otros rituales que los franciscanos introdujeron. 
Las narrativas que cuentan la historia de las relaciones entre las comunidades que circularon entre las antiguas misiones y sus inmediaciones, son resumidas en la Tabla 1.

Tabla 1. Los asentamientos del Putumayo según las narrativas.

\begin{tabular}{|c|c|}
\hline Nombre de la comunidad & Memorias del lugar según las narrativas \\
\hline San Diego - Región de los San Diego bain & $\begin{array}{l}\text { En el tiempo de quina, los curacas de Gantëya } \\
\text { bain causaron una epidemia que acabó con el } \\
\text { Pueblo. Los ataques de brujería fueron realizados } \\
\text { por curacas que estaban transportando quina. } \\
\text { Los sobrevivientes huyeron para el río Guamués }\end{array}$ \\
\hline $\begin{array}{l}\text { San José - nombre en Siona Huë'e } \\
\text { jobo uriya - Pueblo del Rio de } \\
\text { Oro - Región de los San José bain } \\
\text { El nombre asocia a ellos con la extrac- } \\
\text { ción del oro }\end{array}$ & $\begin{array}{l}\text { Epidemias causadas por los curacas de Gan- } \\
\text { tëya bain y después de una epidemia, la } \\
\text { Gente de San José migró para Muse Gunti } \\
\text { lgnacio Grandeeracuracamalodelos San Josébain. } \\
\text { El Río Guamués era el territorio de cacería de los } \\
\text { San José bain. }\end{array}$ \\
\hline $\begin{array}{l}\text { Orito - Comunidad de los San José bain } \\
\text { en el Uriya - río del oro }\end{array}$ & San José bain. \\
\hline \multirow{4}{*}{$\begin{array}{l}\text { Nasotoaró - cerca de un salado (toaró) } \\
\text { del mono churuco (naso) } \\
\text { Local cerca de la vieja misión de Cuembí } \\
\text { Pueblo de Gantëya bain en el final del } \\
\text { siglo XIX }\end{array}$} & \multirow{4}{*}{$\begin{array}{l}\text { El curaca Leonides Yaiguaje vivía aquí. } \\
\text { Un cauchero moreno vivía con ellos y bebió yajé. } \\
\text { Su nombre era Aña Pëquë Chachahuë, o "boca } \\
\text { grande", y sabia transformar en anaconda }\end{array}$} \\
\hline & \\
\hline & \\
\hline & \\
\hline \multirow[t]{2}{*}{$\begin{array}{l}\text { San Antonio - Pueblo de Gantëya bain en } \\
\text { el inicio del siglo XX }\end{array}$} & $\begin{array}{l}\text { Leonides Yaiguaje fue curaca que tomó yajé } \\
\text { cuando faltaba pescado. }\end{array}$ \\
\hline & $\begin{array}{l}\text { Ignacio, del Oyo bain, fue el curaca que trajo yuca } \\
\text { del cielo después de beber yajé. }\end{array}$ \\
\hline \multirow[t]{2}{*}{$\begin{array}{l}\text { Comandante Playa - Pueblo de Gantëya } \\
\text { bain en } 1930\end{array}$} & $\begin{array}{l}\text { Leonides es cacique-curaca y muere aquí. } \\
\text { Manuel Piaguaje es otro curaca. }\end{array}$ \\
\hline & $\begin{array}{l}\text { Una inundación causó que los sobrevivientes } \\
\text { fueran hacía Piñuña Blanca. }\end{array}$ \\
\hline \multirow{2}{*}{$\begin{array}{l}\text { Buenavista - Gonsayá - pueblo de los } \\
\text { Gantëya bain fundado después de la } \\
\text { muerto de Leonides }\end{array}$} & $\begin{array}{l}\text { Arsenio Yaiguaje es cacique hasta que muere en } \\
1962 .\end{array}$ \\
\hline & A 3 días de Puerto Asís, subiendo de canoa. \\
\hline Tigre Playa & $\begin{array}{l}\text { Un patrón cauchero con nombre de Sebero } \\
\text { mandó un joven Siona a cazar un venado y su } \\
\text { espíritu ataca el joven, que muere de fiebre. }\end{array}$ \\
\hline $\begin{array}{l}\text { Remolino - Ne'era huë'e jobo -Pueblo de } \\
\text { Remolino }\end{array}$ & $\begin{array}{l}\text { Un curaca del siglo XIX transforma en boa y vive } \\
\text { aquí. }\end{array}$ \\
\hline
\end{tabular}




\begin{tabular}{|c|c|}
\hline Nombre de la comunidad & Memorias del lugar según las narrativas \\
\hline $\begin{array}{l}\text { Angostura - Crusu Tubë - "Pilar de la } \\
\text { Cruz" } \\
\text { Pueblo multi-étnico de la Gantëya bain } \\
\text { Nombra los Ancutere, Chufi, Oyo, Maca- } \\
\text { guaje, Kofan, Uitoto, Correguaje, Inganos, } \\
\text { Tama, Secoya, Tucano como residentes. } \\
\text { Un asentimiento marcado con una cruz, } \\
\text { que recordaba del período Franciscano. } \\
\text { Hay muchas narrativas asociadas con } \\
\text { este pueblo. }\end{array}$ & $\begin{array}{l}\text { Una comunidad grande (cerca de 1880) con tres } \\
\text { lomas donde el rio se estrecha; tenían fiestas y } \\
\text { bailaron hasta que termino la chicha. } \\
\text { Los Oyo bain cargaron caucho, llegaron a Angos- } \\
\text { tura y dejan rau (brujería) en el puerto, causando } \\
\text { una epidemia. } \\
\text { Una mujer de Crusu Tubë es tragada por una } \\
\text { boa en la bocana de la Quebrada Perfumada } \\
\text { (ma'ñaya). Leonides Yaiguaje es el curaca que vio } \\
\text { lo que pasó } \\
\text { Visita del Padre y como fue bien recibido en fiesta. } \\
\text { Cuando los curas fueron malos y los curacas los } \\
\text { brujearon. Los que sobrevivieron regresaron } \\
\text { para España; los indígenas enterraron las campa- } \\
\text { nas del oro y abandonaron el pueblo. }\end{array}$ \\
\hline $\begin{array}{l}\text { Yocorubë - Santa Helena } \\
\text { Pueblo de los Oyo bain en el inicio del } \\
\text { siglo XX }\end{array}$ & $\begin{array}{l}\text { El cauchero Antonio Figueroa era patrón aquí; y } \\
\text { los Oyo, Gantëya y Macaguaje recolectaron cau- } \\
\text { cho, incluyendo el curaca Leonides Yaiguaje. } \\
\text { Figueroa defendió a los Oyo bain cuando fueron } \\
\text { atacados por los Uitoto río abajo. Pero por mal- } \\
\text { tratarlos en Santa Elena, los Oyo bain lo mataron. } \\
\text { Ignacio Chiquito y Lorenzo eran curacas Oyo. }\end{array}$ \\
\hline Muse Gunti - San José y Gantëya bain & $\begin{array}{l}\text { Pueblo fundado por la gente de San José después } \\
\text { de una epidemia. Tenía una mujer como jefa y } \\
\text { celebraron la Fiesta de Pascua o de San José. La } \\
\text { gente de San José habló diferente que la gente de } \\
\text { Piyuya huë'e jobo, con quien visitaron en fiesta. }\end{array}$ \\
\hline $\begin{array}{l}\text { Piñuña Blanco - Santa Cruz de Piñuña } \\
\text { Blanco - Piyuyá Huë’e Jobo - Gantëya e } \\
\text { San Diego bain }\end{array}$ & $\begin{array}{l}\text { Celebraron Pascua y la llegada de la gente de } \\
\text { otro pueblo, talvez de San Diego. }\end{array}$ \\
\hline Montepa - Pueblo de los Oyo bain & $\begin{array}{l}\text { Vivian los Oyo, Siona y Macaguaje en el tiempo } \\
\text { de caucho. } \\
\text { Mauricio, un curaca Oyo, era malo. }\end{array}$ \\
\hline Río Apaiya - Oyo bain y Macaguaje & $\begin{array}{l}\text { Curacas Oyo mataron la boa con un oso hormi- } \\
\text { guero después de tomar yoco; estaban transpor- } \\
\text { tando caucho. } \\
\text { En las cabeceras de Apaya un curaca Macaguaje } \\
\text { canta y cría una laguna bain ubë sitara. }\end{array}$ \\
\hline Boca de San Miguel & $\begin{array}{l}\text { El curaca Ancutere llamado Antonio vivía aquí } \\
\text { cerca de } 1915-1920 \text { y bebía yajé con los Siona, } \\
\text { compartiendo su conocimiento y narrativas de } \\
\text { los curacas Ancutere. } \\
\text { Él mismo desapareció por } 15 \text { días (cerca 1915- } \\
1920 \text { ) cuando viajó al cielo para se curar. }\end{array}$ \\
\hline
\end{tabular}




\begin{tabular}{|l|l|}
\hline \multicolumn{1}{|c|}{ Nombre de la comunidad } & \multicolumn{1}{|c|}{ Memorias del lugar según las narrativas } \\
\hline Concepción - Pueblo de Oyo bain & $\begin{array}{l}\text { Narrativas cuentan de la Iglesia de piedra que } \\
\text { colapsó, matando muchas personas. Hay memo- } \\
\text { rias de la crueldad de los españoles en Concepción. }\end{array}$ \\
\hline $\begin{array}{l}\text { Boca de Güepi - Actual comunidad de } \\
\text { Consacunti (Gonsagunt) donde vivian } \\
\text { muchos Oyo bain }\end{array}$ & $\begin{array}{l}\text { Un moreno vivía allá y bebió yajé con los curacas. } \\
\text { De la Quebrada Güepi había trocha al Aguarico y } \\
\text { en la Quebrada bë'ëya en el Aguarico, un curaca } \\
\text { crio una laguna; los Siona cargaba caucho en esta } \\
\text { trocha. }\end{array}$ \\
\hline Mie Gunti - Comunidad de Oyo bain & $\begin{array}{l}\text { 2 curacas Oyo, un de Mie Gunti llega como tigre } \\
\text { en Gonsaya para pelear (siglo XIX). } \\
\text { Ignacio es el curaca Oyo de la comunidad. } \\
\text { Narrativa sobre un joven que tomó yajé solo. }\end{array}$ \\
\hline $\begin{array}{l}\text { Caucayá - Comunidad de Oyo bain } \\
\text { - siglo XIX }\end{array}$ & $\begin{array}{l}\text { Parte de la red, el curaca Leonides Yaiguaje de } \\
\text { los Gantëya bain tomó yajé allá. }\end{array}$ \\
\hline - & $\begin{array}{l}\text { Una batalla entre los Oyo bain y Uitoto's sin el } \\
\text { lugar nombrado. Los Oyo tienen una escopeta - } \\
\text { Siglo XIX. }\end{array}$ \\
\hline Angustilla - Ancutere bain & $\begin{array}{l}\text { Narrativa sobre los franciscanos que encerraron } \\
\text { a los curacas y los curacas tomaron yajé para } \\
\text { defenderse; todos los españoles mueren o regre- } \\
\text { san a España. Los indígenas huyen y dejen los } \\
\text { cuerpos podridos. }\end{array}$ \\
\hline
\end{tabular}

Tomadas en conjunto, ellas establecen los territorios e identidades asociadas con los grupos sobrevivientes en el río Putumayo que estaban envueltos en las relaciones del comercio con los blancos, a pesar que estas actividades no son centrales a las narrativas asociada con la época. Según el punto de vista de los Gantëya bain de Buena Vista, las comunidades se relacionaban en redes de intercambio de conocimiento chamánico, de narrativas y de fiestas (Langdon 1981, 1986). Los curacas también defendieron sus asentimientos de los ataques de brujería, que normalmente fueron atribuidos a los chamanes de otros grupos.

La Tabla 1 muestra cómo los Siona recuerdan su ocupación del territorio a través de la memoria de eventos críticos asociados con sus asentamientos y otros lugares en el paisaje. La Figura 1 identifica los asentamientos y otras ubicaciones asociadas con los seis grupos nombrados en las narrativas. ${ }^{13}$

13 Agradecimientos: a Alan Langdon y Cristian Mongua por la diagramación de los mapas. 


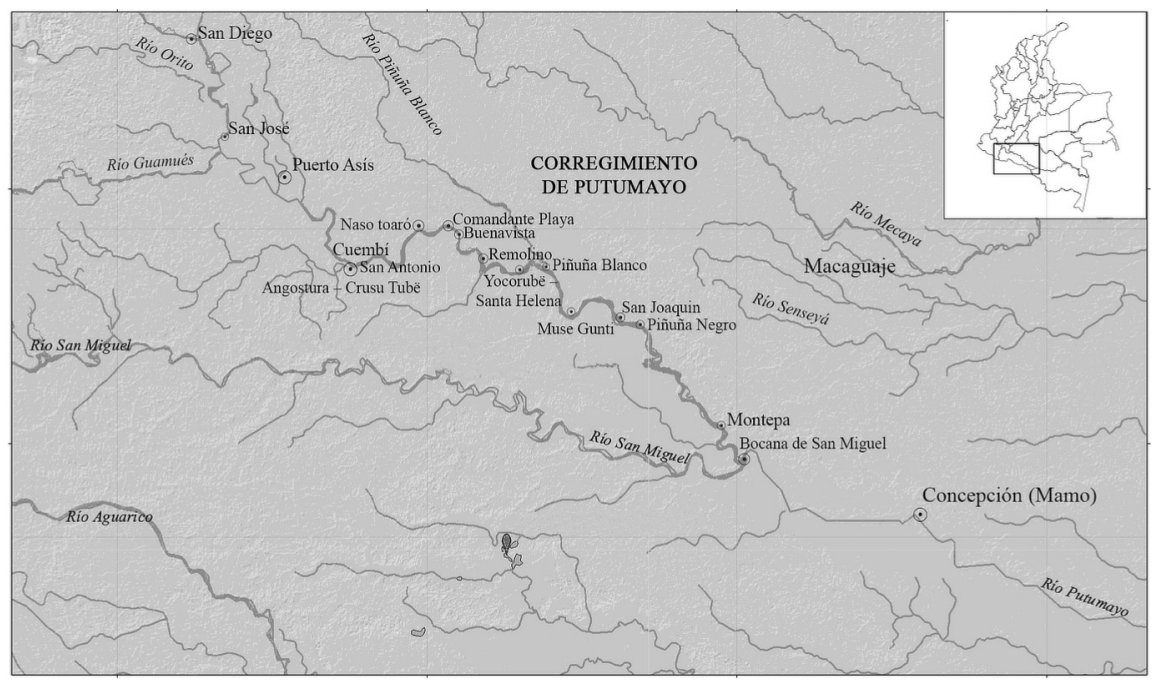

Figura 1. Asentamientos Siona Siglo XIX-XX. Fuente: elaboración propia.

Estas narrativas también identifican los espacios de circulación de los diferentes grupos (Figura 2). Descendiendo el río Putumayo, los grupos según los Siona son la gente (bain) de San Diego y de San José (dos misiones antiguas de los franciscanos); los del Gantëya (del río Putumayo) que circularan alrededor de las misiones antiguas del Cuimbé y de Angostura; los Oyo de Montepa y Concepción; y los Ancutere que estaban más abajo de los Oyo asociados a la misión de Angusilla. Los Macaguaje ocuparon la región entre el Putumayo y Caquetá en esta época, principalmente en el Mecaya y Senseya.

Las narrativas evidencian una importante circulación de los Siona, Oyo, Macaguaje y otros trabajando como bogas o recolectores de las resinas. No obstante, la mayoría de las narrativas que referencian esta época, tratan de epidemias o de otros infortunios causados por las batallas chamánicas entre diferentes comunidades, donde los Siona son los protagonistas de su historia, y los chamanes son las figuras principales, siendo ellos los responsables de la defensa de sus pueblos y protagonistas en la mayor parte de los eventos críticos que constituyen la construcción de su territorialidad en el Putumayo. Las visitas de los curacas a los otros caseríos con fines aparentemente pacíficas de compartir rituales de yajé siempre tenían el potencial para episodios de brujería. 


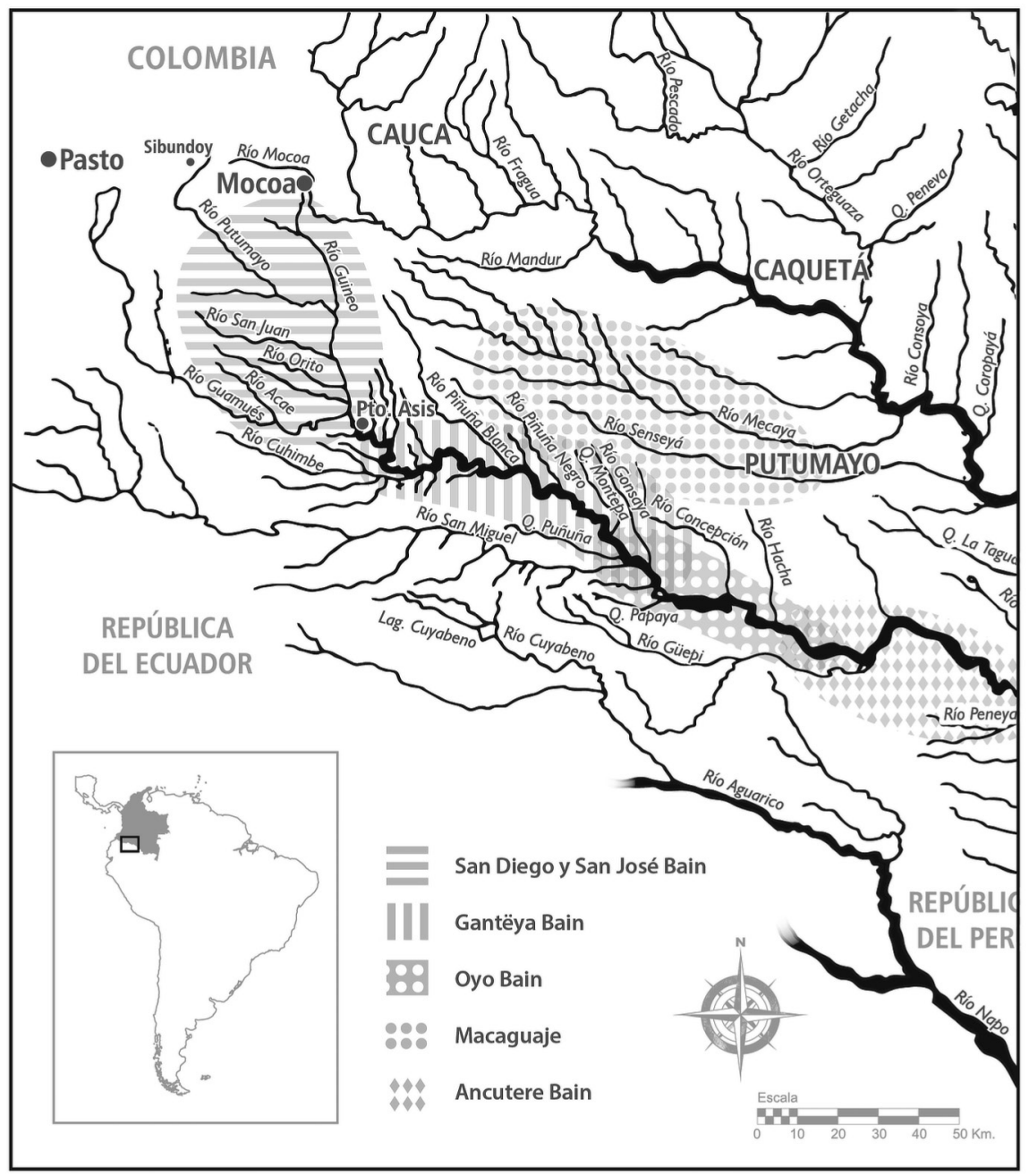

Figura 2. La territorialidad de los Tucano occidentales según las narrativas. Fuente: elaboración propia.

Aunque los Siona no desconocen el hecho de que las epidemias fueron introducidas por los extraños que llegaron con la extracción de resinas, en las narrativas las epidemias figuran como eventos críticos relacionados con las batallas chamánicas entre curacas rivales de diferentes comunidades. Como podemos 
ver en el resumen de las narrativas de la Tabla 1, la epidemia que resultó con el fin de la gente de San Diego, fue causada por los curacas de la Gantëya bain. El drama social se inicia con el asesinato de un curaca Ancutere que vivía en San Diego. Las noticias de su muerte fueron comunicadas a los Siona y Ancutere por los Oyo, que estaban transportando quina a lo largo del río Putumayo. Los curacas de los Gantëya tomaron represalias, durante un viaje en el que transportaban quina cerca de esta localidad. Dejaron el "brujo" de huehue rau en el puerto de San Diego, causando que toda la comunidad enloqueciera y muriese por altas fiebres. En otra historia que se puede localizar en esta misma época, los curacas Oyo, que cargaban caucho, pararon en Angostura, un pueblo de la gente Gantëya. En su visita se enojaron porque las señoritas se les ocultaban. Ellos dejaron un "brujo" (rau - objeto de brujería) en el puerto del río, causando que toda la gente se enloqueciera con altas fiebres producidas por sarampión, destruyendo la mayor parte de la aldea. Los curacas Gantëya tomaron venganza, viajando a Montepa para dejar el brujo (rau) de sarampión en su puerto para contagiar a los Oyo, y así sucesivamente, lo que llevó a la desaparición de un gran número de aldeas en el Putumayo.

Las narrativas contadas por los ancianos que nacieron antes, o a comienzos del siglo XX, nos permiten mapear la circulación de los diferentes grupos asociados con los cacique-curacas. Los habitantes de San Diego y San José fueron diezmados por las epidemias, algunos sobrevivientes terminaron trasladándose al territorio de la gente Gantëya y se casaron con ellos. Los Gantëya circularon por diferentes lugares aguas abajo de Puerto Asís, incluidos Cuembé, Nasotoaró, Santo Antonio, Comandante Playa, Yocorobë, Santa Elena, Angostura y Piñuña Blanca de Santa Cruz. Se casaron con los Oyo bain, que fueron identificados con los asentamientos de Yocorobë, Montepa y Concepción. Los Oyo llegaron a disputar el territorio río abajo con los Huitoto, y sufrieron más con los patrones caucheros que los Gantëya. Los Ancutere vivían aún más abajo, cerca de Concepción y Ancusilla, pero huyeron a Ecuador al final del boom del caucho. Como lo indica la narrativa de la Ciudad de Wayusañë, los Chufi, también conocidos como Tetete, fueron expulsados del río Putumayo en batallas cerca del actual Puerto Asís (las quebradas de Chufiyá, Singuyá, Cocayá) y huyeron para Ecuador. Los Macaguajes tradicionalmente ocuparon en el interior entre el río Putumayo y Caquetá y también 
estuvieron sometidos a patrones caucheros. Al final de la época del caucho, estaban a punto de desaparecer como consecuencia de las epidemias, trasladándose al río Putumayo, fundando San Joaquín en 1938, donde se casaron con los Siona (Friede, 1952). Los residentes de Buenavista hoy día se identifican como un grupo único, los Gantëya, pero las genealogías demuestran que varios tienen padres o abuelos que anteriormente fueron identificados con los otros grupos de Tucano occidentales mencionados en las narrativas (Macaguaje, Oyo, San Diego, San José).

\section{La construcción del territorio Siona en las fuentes documentales}

Las fuentes documentales oficiales del estado colombiano (Territorio del Caquetá) y eclesiásticas (religiosos de la compañía de Jesús, sacerdotes seculares y misioneros capuchinos) de las misiones católicas, permiten identificar y correlacionar los asentamientos de los Tucano occidentales y situarlos en medio del establecimiento de esta nueva jurisdicción y la construcción de la territorialidad de los Siona entre 1870 y 1930. Los informes de las autoridades colombianas y las excursiones apostólicas de los misioneros dan cuenta de estos asentamientos a lo largo de la segunda mitad del siglo XIX y las primeras décadas del siglo XX, los conflictos con los caucheros y las enfermedades que azotaron a sus poblados, y la crisis de sus asentamientos en este último siglo. En estas fuentes documentales se encuentran referencias a los asentamientos más importantes de la etnohistoria Siona: San Diego, San José, Cuimbé, Montepa, Macaguajes y Concepción (Mamo) (Figura 1), las cuales se complementan y correlacionan con las narrativas etnohistóricas de los Siona.

A partir de la documentación escrita es posible rastrear estos asentamientos. Por ejemplo, en el de 1847 el secretario del Territorio del Caquetá José María Quintero ${ }^{14}$ informó de los avances materiales que se habían llevado a cabo en los pueblos del corregimiento del Putumayo:

14 El secretario del Territorio del Caquetá redactó en este año un extenso informe a las autoridades centrales de la Nueva Granada un panorama detallado de las condiciones en que se encontraba este territorio tras el abandono de las misiones franciscanas a finales del siglo XVIII. Para $\rightarrow$ 
Que en San Diego de San Juan se está construyendo la casa parroquial, se ha empedrado el puerto o desembarcadero de dicho pueblo y se trata con actividad de fomentar y arreglar su caserío. Que en San Diego del Putumayo se ha dado órdenes para limpiar y ampliar la localidad, y para acopiar maderas aparentes para construir una iglesia que en el pueblo de Cuimbé se han levantado una capilla y cada parroquia que se ha reducido a una localidad fija la parcialidad de indígenas llamados picudos, que se hallaban dispersos. Que en el pueblo de Mamo, anteriormente llamado "Concepción" se ha concluido una espaciosa y bien ordenada capilla, debido al celo e interés del Señor Presbítero Francisco Antonio Velasco misionero de aquellas poblaciones; que personalmente se ha ocupado en aquel trabajo.

Que en la parcialidad de Macagnayer (Macaguaje) se ha despejado el bosque, construido una capilla y abierto el camino que atraviesa del río Putumayo al Caquetá. Que los indígenas de Cancapuí, los cuales se había separado de la obediencia a las autoridades, han vuelto a ella, y se hallan con buenas disposiciones. ${ }^{15}$

La intención del secretario era destacar su labor en esta nueva jurisdicción de la Provincia del Cauca, destacando el avance material de los "pueblos", dando a entender que estos habían sido construidos bajo su mandato. Llama la atención los poblados que son relacionados por Quintero, asentamientos que hacen parte de las narrativas etnohistóricas de los Siona. La adecuación de las capillas y la construcción de estos pueblos hizo parte de las formas de organización heredadas por las misiones francisanas. Además, la adecuación de estos espacios hizo parte de la llegada de sacerdotes seculares de Popayán y el establecimiento de los misioneros de la Compañía de Jesús en 1846.

$\rightarrow$ entonces el interés de Colombia se centró en ejercer presencia sobre las fronteras indefinidas del Napo, Aguarico, Putumayo y Caquetá, territorios que reclamaba como pertenecientes a su jurisdicción tras la separación de la Gran Colombia en 1830.

15 Archivo General de la Nación, Bogotá, Colombia. Sección República, Fondos. Ministerio de Relaciones Exteriores (MRE), Anexo II, caja $\mathrm{n}^{\circ} 3$, carpeta 0018, ff. 37. 


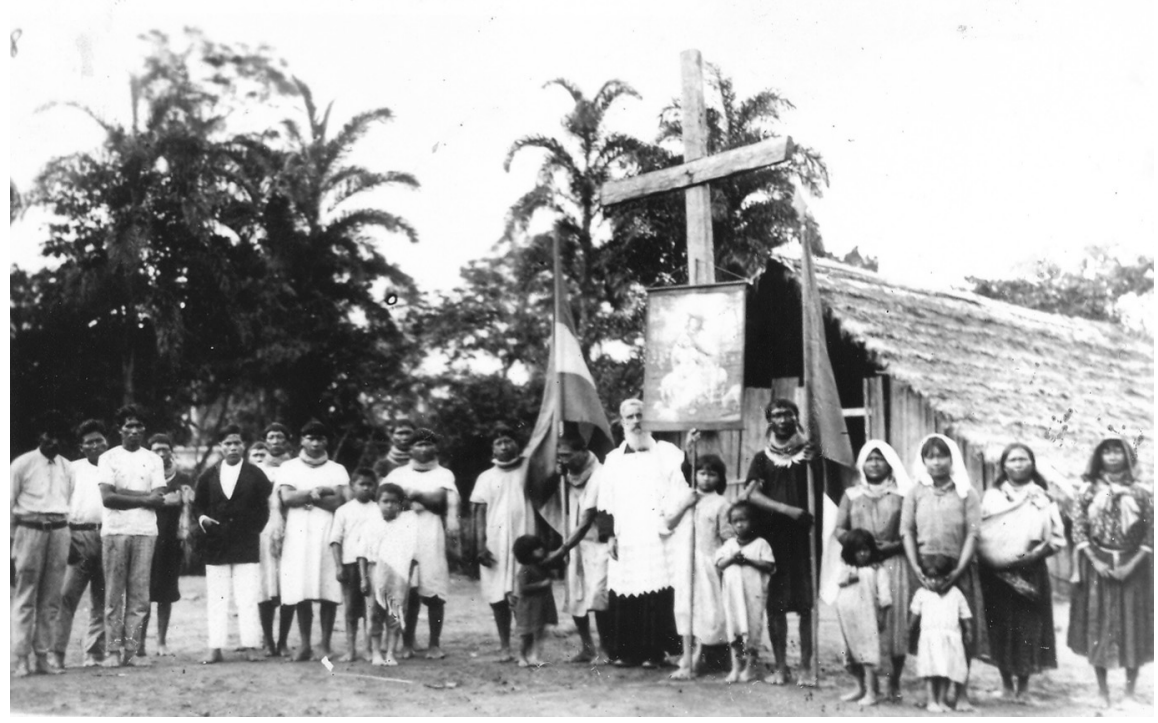

Figura 3. Un padre capuchino en el río Putumayo con Tucano occidentales, sin identificación o fecha. Fuente: Archivo Hermanos Menores Capuchinos.

El padre Laínez entre 1876-1878 visitó los asentamientos Siona de San Diego, San Diego nuevo (San José), Cuimbé, Montepa, y Macaguajes, resaltando en sus excursiones la manera cómo los indígenas le recibían a su llegada y el conocimiento de Dios por parte de estos grupos, a los que llamó las áreas "cristianas" del Putumayo. Resulta interesante observar una de sus descripciones de su visita al asentamiento de Macaguajes y la manera como vestían estos indígenas:

Terminada tan felizmente mi excursión en el río Putumayo, deja las canoas para empuñar mi bordón y meterme en las selvas. Salí al rio Sensella y al Mintoya, cuyas vueltas y revueltas me habían de servir de norte y guía para dar con la tribu de los Macaguajes. Anduve a pie un día entero y entre corpulentos y encumbrados arboles encontré la ranchería de estos indios, los más pacíficos y sencillos de cuantos he tenido la dicha de visitar. Son tan recatados y decentes, que ya en su pobreza no encuentran como vestirse de lienzo, según usan los otros indios, se cubren con la corteza de un árbol llamado Carapacha. (Pérez, 1896-1898, p. 182). 
En 1854 el Presbítero Manuel María Albis realizó una importante crónica de su visita a estos mismos asentamientos visitados posteriormente por Laínez. En San Diego describió los conflictos entre los asentamientos del Putumayo, destacando el "soplo" de los médicos para curar a sus pacientes, enfermedades que atribuyen a las brujerías de sus vecinos y a lo que denominó los "enredos de los brujos" (Domínguez; Gómez; Barona, 1997, p. 107). En su paso por Montepa y Caucaya destaco las actividades económicas a las que se dedicaban, el lavado de oro y la extracción de cera y cacería. En el transcurso de la segunda mitad de este siglo, el comercio y las actividades extractivas aumentaron en el territorio de los Tucano occidentales (cera y el lavado de oro), lo que llevó al incremento de extraños en sus asentamientos.

Para la década de 1870 el Prefecto Maximiliano Díaz informó la composición de los pueblos del corregimiento del Putumayo, en donde además de la continuidad de los de San Diego, San José, Cuembí, Picudos, Montepa, Micuntí, los Macaguajes habían establecido nuevas localidades: "los caseríos (monte adentro) de los Macaguajes de Montepa, Macaguajes de la Concepción, Macaguajes de Lurilla, Caucaya y muchos caseríos de los Orejones, tratables unos y otros no, que están situados en varios afluentes del Putumayo, desde Micunti hasta el Marañon: su capital, San Diego". ${ }^{16}$

Aunque los informes oficiales permiten rastrear a lo largo de la segunda mitad del siglo XIX los asentamientos Tucano occidentales, es escasa la información que proporciona acerca de sus habitantes. Las fuentes documentales de los misioneros capuchinos ofrecen un mayor detalle de quiénes vivían en estos y de la movilidad de estos grupos. En 1893 Fray Ángel de Villava visitó los grupos indígenas de la cuenca media del río Putumayo, los cuales se encontraban inmersos en la economía gomífera. En su excursión denunció la presión ejercida por los comerciantes caucheros en San José, y la molestia de los indígenas por la presión de los comerciantes caucheros y su intención de trasladarse al río Guamués:

Los habitantes de San José nos dieron pruebas de afecto y confianza, y nos dieron cuenta de ciertos hechos de los comerciantes, que merecen castigo. Quejaronse de la conducta que algunos blancos observan con ellos, y nos dijeron que

16 Archivo Central del Cauca, Sección República, Fondo Inactivo, Paq., 119, Lg., 26. s/f. 
todos unánimemente estaban resueltos a trasladarse al río Guamués, porque los comerciantes los molestan mucho y no les dejan tiempo para cultivar sus chagras. (Villava, 2002, p. 51).

En 1898 Fray Antonio María de Calamocha corroboró la movilidad de los Tucano occidentales, destacando la movilidad de los indígenas de San Diego y San José, quienes viajaban constantemente al Marañón e Iquitos. En su excursión documentó el trasladado del pueblo de San José, quienes se habían ubicado en las inmediaciones del antiguo puerto quinero de la Sofía. En San Diego señaló que encontró al comerciante cauchero Leónidas Ramírez conviviendo con los indígenas:

A la vista del pueblo hicimos descargas de escopeta, (señal convenida) a cuyas descargas contestaron otras desde el pueblo, disparadas por algunos blancos residentes en dicho pueblo, entre ellos el entusiasta D. Leónidas Ramírez y sus colonos; también los indios celebraron mi llegada con repique de campanas, saliendo a recibirme el gobernador con los cuales en medio de repiques de campana y tambores me condujeron a la casa-convento. (Calamocha, 2002, p. 147).

Además del traslado de San José, sus habitantes se encontraban enfermos:

Después de haber visitado las casas o ranchos, pues la mayor parte de los indios se hallaban enfermos de romadizo y disentería, enfermedades que diezman estos pueblos. No se olvida de decirme todos: Pasame bonito, taita padre, pronto mírame mío, San José, gente mucho quiere que tenga bien viaje padre; ven pronto de visitarnos. (Calamocha, 2002, p. 163).

En este período son comunes las enfermedades en estos grupos registradas por los misioneros como gripes, sarampión y otras enfermedades. A la llegada de los religiosos algunos de estos grupos demostraron una receptividad inusual a la realización de los rituales de matrimonio y bautismo, estableciendo los misioneros capuchinos relaciones con algunos de los cacique-curacas, los líderes chamanes de las comunidades. En este contexto, los misioneros compitieron con los patrones caucheros, a través de una estrategia que consistió en relocalizar a las familias indígenas en asentamientos más cercanos a la misión. 


\section{Territorialidad indígena y construcción del espacio misionero}

La entrada del siglo XX marcó un cambio sustancial en el contexto del Putumayo. La creciente demanda de gomas llevó a una presencia permanente de los comerciantes caucheros en los asentamientos indígenas. La guerra de los mil días de Colombia (1899-1903) fue un factor importante que llevó al establecimiento de una misión católica, tras la victoria del partido conservador.

Estos sucesos llevaron a la creación de la Prefectura Apostólica del Caquetá y Putumayo en 1904, y la asignación de los extensos territorios del Aguarico, Napo y Putumayo a la misión capuchina. Con el paso de los años se fue estableciendo una nueva percepción de territorialidad, que involucró los pueblos indígenas de la cuenca media del río Putumayo, generando un fuerte conflicto con los caucheros de la región. Los misioneros capuchinos de la Prefectura Apostólica se esforzaron en materializar su proyecto de una gran ciudad en el río Putumayo que agrupara los grupos indígenas del Putumayo, San Miguel y Aguarico.

Los asentamientos indígenas de los Tucano occidentales se convirtieron en el centro de disputa de los caucheros y capuchinos, en donde estos últimos se centraron en frenar la influencia de los caucheros sobre los indígenas. Pese a este conflicto, tanto los caucheros (quienes eran autoridades políticas) y los misioneros utilizaron estos asentamientos para establecer su jurisdicción. ${ }^{17}$

Un interesante ejemplo de estas nociones de territorialidad puede encontrarse en los informes de las excursiones apostólicas de la misión capuchina. Fray Jacinto María de Quito, en su viaje a Iquitos de 1908, visitó los caseríos Siona del río Putumayo. En este viaje constató la manera de gobernarse de los indígenas y la continuidad de los asentamientos, los cuales, aunque podían trasladarse de un lugar a otro, se ubicaban en una región cercana, conservando el mismo nombre:

17 A nivel nacional, Colombia utilizó la existencia de estos asentamientos a su favor al reclamar su soberanía sobre este territorio, argumentando su presencia en este río a través de la existencia de "los pueblos del corregimiento del Putumayo". 
[...] llegamos al primer pueblo de indios llamado San Diego, sitio en la ribera izquierda del Putumayo. Pocos minutos antes de nuestro arribo sus moradores ya nos pudieron ver, y como tienen vista de lince nos les costó mucho reconocerme [...] Finalmente, la cosa se puso seria cuando el Cacique o Capitán (así llaman a quien gobierna al pueblo), con una vara en la mano, insignia de su autoridad, empezó a descender la bajada que media entre la plaza y el río, y le seguían los magnates del pueblo como también la muchedumbre toda [...] Ahora ocupemos algún tanto de nuestros dieganos. Debo advertirle que tanto lo bueno como lo que no lo sea es propio no solo de los dieganos, sino también de los indígenas de San José, Yoasotoaró y Montepa [...] En el Putumayo sólo son cuatro los pueblos que hablan el Siona, siendo aproximadamente unos 250 sus habitantes; y como todos emplean el castellano para comunicarse con los blancos y los demás indios que no poseen tal dialecto, verbigracia. (Jacinto de Quito, 1908, p. 11-12).

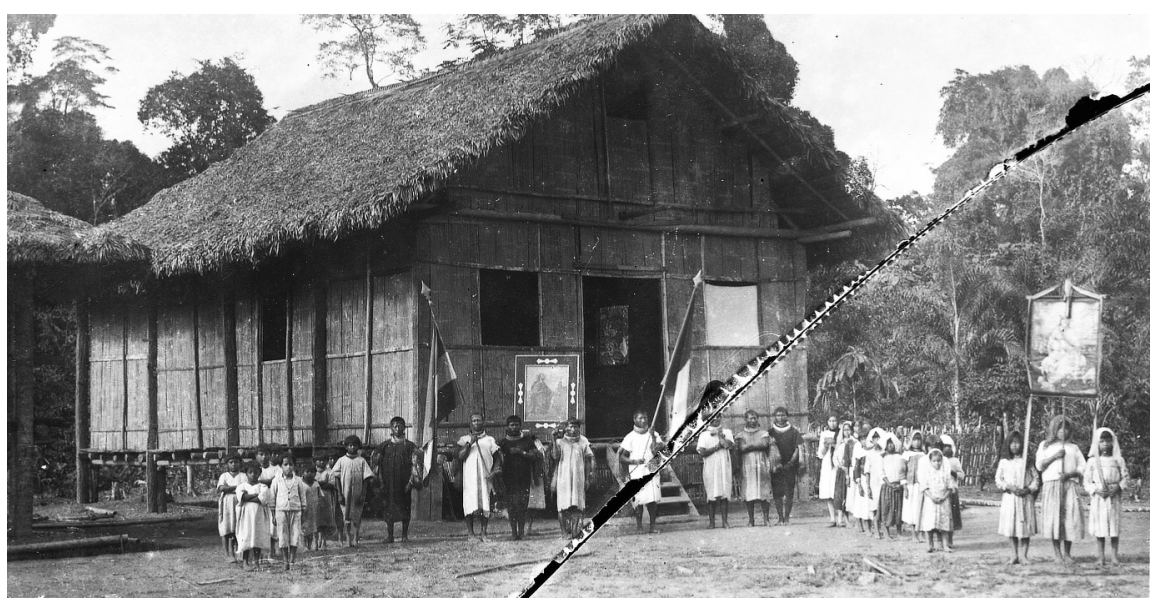

Figura 4. Pueblo Indígena Siona: capilla y fiestas católicas. Fuente: Archivo Histórico Hermanos Menores Capuchinos.

En su expedición visitó el caserío de Yasotoaró [Nasotoaró], que para entonces se ubicaba próximo a la desembocadura del río Cuembí, a unas diez leguas de este poblado: "Los habitantes de este lugar son de iguales costumbres y dialecto de los ya mencionados. Su población total no pasará de unas setenta almas" 
(Jacinto de Quito, 1908, p. 18). En este mismo año Fray Ildefonso de Tulcán realizó una excursión entre el Valle del Guamués, Aguarico y el río Putumayo. En su paso por San Diego documentó el abandono de este lugar, y la construcción del nuevo pueblo en el Trejo: "Ese pueblo viejo mucha enfermedad tiene; por eso nuevo pueblo trabajando" (Tulcán, 2002, p. 110). En el punto de la Sofía los indios de San José continuaban estableciendo allí su residencia, a la cual se trasladaron en el año de 1898, como había informado Calamocha.

En el intermedio del trayecto entre Yasotoaró y Montepa, Fray Idelfonso de Tulcán visitó el pueblo de Yocoropuí, ubicado en cercanías de la quebrada de Piñúña (Blanco), y denominada por los Siona como Piyuyá: "que significa Río de tucán o dios de chiquito, a la derecha del Putumayo" (Tulcán, 2002, p. 137). En este lugar Tulcán encontró la finca del cauchero Arsenio Figueroa, "Santa Helena". Describió a la "gente de Montepa" como pertenecientes a los añaguajes - culebras -, quienes en algunas ocasiones vivían en aquel lugar, o se trasladaban a algún punto cercano. En su viaje al Putumayo relató un interesante encuentro que permite ubicar los territorios en donde se encontraban para entonces los Chufi o Tetetes, aucas y enemigos de los Siona en las narrativas, con quienes se disputaron su territorio (Wasserstrom; Reider; Rommel, 2011). En su trayecto a la Concepción, en la desembocadura del río San Miguel, el misionero narró los temores de ataques por parte de los Tetetes:

El Putumayo estaba bastante crecido, de modo que empujaba al San Miguel, llegó la noche y se oyeron unos grupos largos; iú, ú, ú! jah, ah, ah! que venían del Putumayo. Nadie hizo caso; pero gritan segunda vez, y el Padre Jacinto, algo preocupado, me dijo:-Hermano, ¿no oye gritar? -y estoy oyendo, le respondí. ¿No serán los tetetes? (indios muy salvajes e infieles, que vagan entre el Aguarico y el San Miguel). No puede ser, porque sin fueron los Tetetes vendrían por San Miguel, y calladitos para darnos el asalto. Estos deben ser Montepas, que vienen a vernos. (Tulcán, 2002, p. 134).

En la desembocadura del río San Miguel, lugar en donde se encontraba localizado la Concepción, no encontraron a los indígenas. Estas expediciones narraron la difícil situación de Guepí para 1908, pueblo que se encontraba en una fuerte decadencia y en donde estaba la agencia cauchera de Antonio Ángel. Tulcán encontró familias de indígenas Huitotos provenientes de las cabeceras 
del Pebeneya, quienes se encontraban trabajando para los comerciantes caucheros. Las excursiones se convirtieron en la principal estrategia de los misioneros para relacionarse con los grupos Tucano occidentales del Putumayo, y a su vez, de ir demarcando una nueva territorialidad a través de la jurisdicción eclesiástica. ${ }^{18}$

Con la fundación de Puerto Asís los misioneros llevaban a los grupos indígenas para que trabajasen en la construcción de la ciudad, con la intención de irlos convenciendo para que se establecieran en esta ciudad.

En la construcción están trabajando hombres, mujeres y niños Indígenas de San José. Los indios de San Diego abandonaron su pueblo que tenía 4 años de fundado y se situaron frente a la casa que están construyendo. Los niños indígenas que están llegando a la Colonia no hablan el Inga ni el coche que son las lenguas que los Misioneros han aprendido (cuentan 4 lenguas diferentes a las aprendidas). Llegarán indios de Ocano que viven en la orilla del San Miguel a 2 días de distancia. También llegarán los indios del Guamués a 2 días de distancia. Yocoropui a 3 días. Montepa a 4 días. ${ }^{19}$

La territorialidad indígena y la construcción de su identidad asociada a los asentamientos, por ejemplo, "la gente de San Diego" "la gente de San José" fue uno de los principales impedimentos para la misión capuchina y su proyecto de concentrar a los Tucano occidentales en Puerto Asís. Este proyecto trajo consigo conflictos tanto con los comerciantes caucheros, como con los taitas-curacas de estas localidades, quienes se oponían a trasladarse a Puerto Asís. Los grupos indígenas continuaron permaneciendo en sus pueblos, en donde se abrieron algunas escuelas y continuaron conviviendo con los comerciantes itinerantes en sus caseríos, lo que provocó fuertes epidemias que impactaron las escuelas de la misión y las comunidades indígenas, causando una disminución significativa de la población y el final de comunidades enteras, llevando a que muchos de los sobrevivientes se reagruparan en otros lugares. De 1900 a 1930 la población Siona pasó de ser aproximadamente 1000 a 250, una reducción de más del 70\% (Langdon, 2014). En la década de 1930, los asentamientos

18 Archivo Histórico Diócesis Mocoa-Sibundoy, 1907, s/f.

19 Archivo Histórico Diócesis Mocoa-Sibundoy, 1912, s/f. 
de San Diego y San José habían desaparecido, y los grupos identificados como Macaguaje, Oyo, Ancutere (al menos en el Putumayo) y Tetete quedaron reducidos con pocos sobrevivientes (Figura 5).

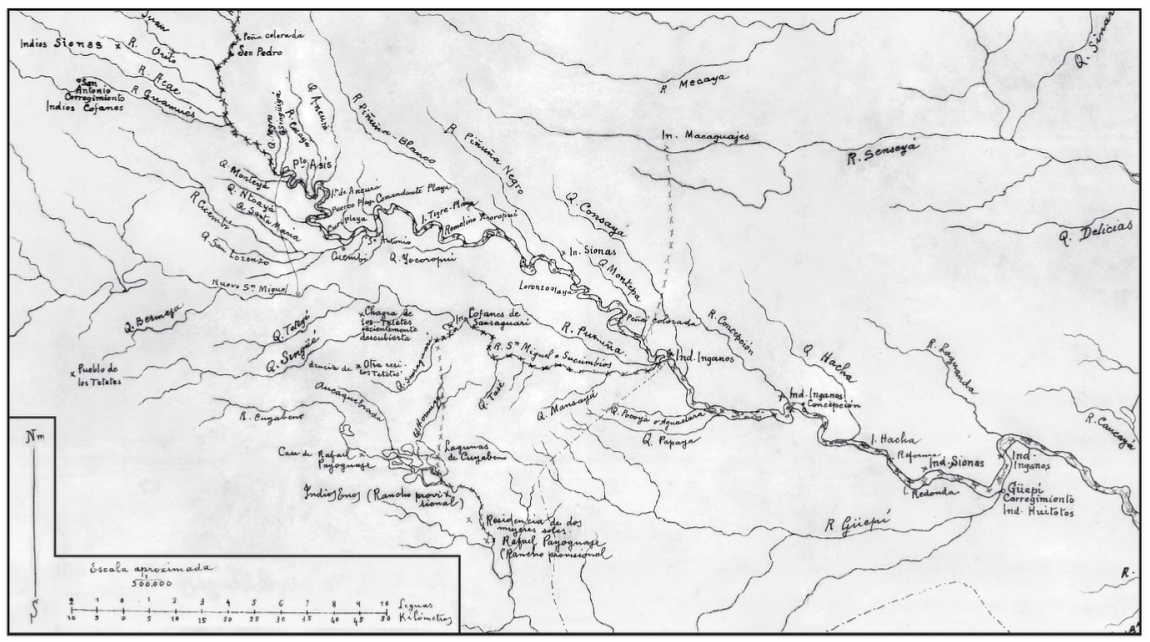

Figura 5. Asentamientos en el Putumayo tras las epidemias de la década de 1920. Fuente: Archivo Histórico Hermanos Menores Capuchinos.

\section{Consideraciones finales}

En este artículo, exploramos la consciencia histórica de los indígenas Siona, que establece su territorialidad en el medio río Putumayo como expresada en un conjunto de narrativas que pueden ser identificadas con el período extractivista de quina y caucho (1874-1930). Las narrativas nos cuentan de seis grupos, que se distinguieron entre si por la región que ocuparon a lo largo del río y en el monte, grupos al mismo tiempo estrechamente unidos por compartir un mismo idioma y una misma visión cosmopolítica, que abarca las relaciones entre los mundos de lo visible y lo invisible, asociados con el espació biofísico. Las memorias de estos grupos y sus relaciones son asociadas con ubicaciones específicas en el paisaje, lugares asociados con eventos críticos, que componen las tramas de las narrativas. Las narrativas también asocian a los grupos con las 
viejas misiones franciscanas. La narrativa que cuenta del origen de los Gantëya bain en el Putumayo colapsa dos períodos: el evento del contacto con los primeros franciscanos en el siglo XVII, con una situación del contacto del siglo XIX (Turner, 1988), donde los Siona manifestaban saber sobre Cristo desde antes de la llegada de los capuchinos. Siempre relataron su orgullo, en los años de 1970, de ser civilizados, en contraste con sus enemigos Chufi, los aucas que echaron del Putumayo en batalla. Las narrativas también recuerdan de las festividades y celebraciones del día de Pascua y las visitas de los capuchinos. Se elaboraron pocas narrativas sobre conflictos con los capuchinos o con los caucheros.

A través de las narrativas, podemos observar que el siglo XIX representó para los Tucano occidentales un proceso de ocupación y despliegue de su territorialidad, a partir de dos elementos, principalmente: la identificación de los grupos sociales con las localidades de las antiguas misiones, y la figura del cacique-curaca. Es importante resaltar que este papel de liderazgo era una reconfiguración, incorporando aspectos del papel de los amos franciscanos. Los pueblos de San Diego, San José, Cuimbé, Concepción, Montepa y otros, no solo pueden analizarse únicamente como la existencia de pueblos ribereños en el siglo XIX, sino por el contrario, como localidades que contienen una importancia trascendental en el proceso de reconfiguración de la territorialidad, organización socio-política e identidad. Esta reconfiguración de su modo de ocupar (Little, 2002) es expresado en las narrativas a través de la memoria de los eventos críticos asociados con estos espacios y con los curacas como sus protagonistas centrales.

Las fuentes documentales analizadas en este artículo coinciden con la etno-etnohistoria de los Siona. A la llegada de los primeros funcionarios del Territorio del Caquetá y los misioneros capuchinos, se encontraron con grupos indígenas que se identificaban y circulaban alrededor de las localidades de las misiones franciscanas. Los capuchinos encontraron algunos pueblos todavía organizados alrededor de una plaza con una cruz, como descrito en las memorias Siona sobre Cruzu tubë (Angostura), nombrado por su "pilar de cruz". Las fuentes escritas también documentan la destrucción de los pueblos a causa de las epidemias, la circulación de las comunidades por causa de estos desastres, y también de las brujerías entre los pueblos enviadas por sus curacas.

El contraste en los procesos de construcción de territorialidad Siona con los proyectos estatales del siglo XIX, y de las misiones católicas, indica la manera como estos diferentes actores comprendieron este territorio. Como se observó, 
para los Siona, la territorialidad vincula tanto lo biofísico como lo invisible y lo emotivo. Para el Estado, las localidades o los pueblos se convirtieron en una importante referencia para sus pretensiones de ejercer soberanía sobre las fronteras indefinidas del Putumayo, contestando a la presencia de los caucheros peruanos. Talvez por esto, sus documentos relatan mayor presencia e importancia de las relaciones laborales que los caucheros tenían con las comunidades indígenas.

Para los capuchinos, su buena recepción en los asentamientos indígenas, las fiestas y la existencia de capillas fueron elementos que interpretaron como evidencia de su domino sobre los indígenas. Pero para los Siona, el cura no representaba una figura superior ni con derecho de mandar sobre ellos. El papel de aconsejar y ordenarles fue otorgado a los curacas por Dios, y el beneficio de tener la presencia de los curas entre ellos fue por otros motivos, sean estos los deseos de practicar de nuevo los rituales católicos, o por la expectativa de que los curas los protegieron contra los engaños de los caucheros.

\section{Referencias}

ALBERT, B. Cosmologias del contacto no Norte-Amazônico. In ALBERT, B.; RAMOS, A. R. (org.). Pacificando o branco: cosmologias do contato no Norte-Amazônico. São Paulo: Editora Unesp: Imprensa Oficial do Estado, 2002. p. 9-23.

ALBERT, B.; RAMOS, A. R. (org.). Pacificando o branco: cosmologias do contato no Norte-Amazônico. São Paulo: Editora Unesp: Imprensa Oficial do Estado, 2002.

BARCLAY, F. Olvido de una Historia. Reflexiones acerca de la historiografía Andino-Amazónica. Revista de Índias, v. 61, n. 223, p. 493-511, 2001.

BASSO, E. The last cannibals. Austin: University of Texas Press, 1995.

BAUMAN, R.; BRIGGS, C. Poetics and performance as critical perspectives on language and social lif. Annual Review of Anthropology, v. 19, p. 59-88, 1990.

CALAMOCHA, A. Excusión llevada a cabo por el P. Fray Antonio María de Calamocha a los pueblos del río San Miguel de Sucumbíos, santa Rosa, San José de Aguarico y otros pueblos del río Putumayo. In: RECALDE, J. A. Misioneros capuchinos ecuatorianos. Cuenca: Impreso Editorial, 2002. p. 143-174. 
CASEMENT, R. Putumayo, caucho y sangre: relación al Parlamento Inglés (1911). Quito: Abya-Yala, 1988.

CASTELlVÍ, M. de. Censo indolinguistico de Colombia. Leticia: Prefectura Apostólica, 1962. (Amazonia Colombiana Americanista, t. 6, 1954-1962, n. 11 extra y 20-34).

DOMÍNGUEZ, C.; GÓMEZ, A.; BARONA, G. Viaje de la comisión corográfica por el territorio del Caquetá 1857. Bogotá: Fondo Fen Colombia, 1997.

FRIEDE, J. Los kofán: una tribu de la alta Amazonía colombiana. In: INTERNATIONAL CONGRESS OF AMERICANISTS, 30., 1952, Cambridge. Proceedings... London: Royal Anthropological Institute, 1952. p. 202-219.

GÓMEZ LÓPEZ, A. J. Amazonia colombiana: contacto-contagio y catástrofe demográfica indígena. Maguaré, v. 13, p. 133-163, 1998.

GÓMEZ LÓPEZ, A. J. Fragmentos para una historia de los Siona y de los Tukano Occidentales. Revista Inversa, v. 1, n. 2, p. 80-107, 2006.

GÓMEZ LÓPEZ, A. J. Indios, misión, colonos y conflictos (1845-1970): fragmentos para una historia de los procesos de incorporación de la frontera Amazónica y su impacto en las sociedades indígena. Popayán: Editorial Universidad del Cauca, 2010.

HILL, J. (ed.). Rethinking history and myth: indigenous South American perspectives on the past. Urbana: Illinois University Press, 1988.

HUGH-JONES, S. The palm and the Pleyades: initiation and cosmology in Northwest Amazonia. New York: Cambridge University Press, 1979.

JACINTO DE QUITO, M. Relacion de viaje en los Ríos Putumayo, Caraparaná y Caquetá y entre las tribus Güitotas. Bogotá: Imp. de "La luz", 1908.

KOHN, E. Infidels, virgins, and the black-robed priest: a backwoods history of Ecuador's Montaña Region. Ethnohistory, v. 49, n. 3, p. 545-582, 2002.

LANGDON, E. J. Social bases for trading of visions and spiritual knowledge in the Colombian and Ecuadorian Montaña. In: ANNUAL CONFERENCE, 20., 1981, Calgary. Networks of the Past: proceedings... Calgary: The Archaeological Association of the University of Calgary, 1981. p. 101-116.

LANGDON, E. J. Las clasificaciones del yagé dentro del grupo Siona: etnobotánica, etnoquímica e historia. América Indígena, v. 46, n. 1, p. 101-116, 1986. 
LANGDON, E. J. La historia de la conquista de acuerdo a los Indios Siona del Putumayo. In: PINEDA CAMACHO, R.; ALZATE ANGEL, B. Los meandros de la Historia em Amazonia. Quito: Abya-Yala, 1990. p. 13-41.

LANGDON, E. J. La negociación de lo oculto: chamanismo, medicina y familia entre los Siona del bajo Putumayo. Popayán: Editorial Universidad del Cauca, 2014.

LANGDON, E. J. The value of narrative: memory and patrimony among the Siona. Revista del Museu de Antropologia, v. 11, supl. esp. 1, p. 91-100, 2018a.

LANGDON, E. J. Dialogicalidad, conflicto y memoria en etnohistoria siona. Boletín de Antropología, Medellín, v. 33, n. 55, p. 56-76, 2018b.

LANGDON, E. J. Perspectivas de los Siona sobre el período extractivo en el Alto Putumayo: memorias de eventos críticos, el mundo no humano y los protagonistas chamánicos. In: ETNOHISTORIA: miradas conectadas y renovadas. Quito: FLACSO. En prensa.

LÉVI-STRAUSS, C. The savage mind. Chicago: The University of Chicago Press, 1966.

LITTLE, P. E. Territórios sociais e povos tradicionais no Brasil: por uma antropología da territorialidade. Brasília: DAN/UnB, 2002. (Série Antropologia 322).

MONGUA CALDERÓN, C. Formaciones estatales en las fronteras amazónicas: religiosos, comerciantes e indígenas en el Putumayo-Aguarico (1845-1904). 2018. Tesis (Doctorado en Historia) - FLACSO Ecuador, Quito, 2018.

MONGUA CALDERÓN, C. Fronteras, poder político y economía gomífera en el Putumayo-Aguarico: más allá de la marginalidad y el aislamiento, 1845-1900. Historia Crítica, n. 76, p. 49-71, 2020.

MONGUA CALDERÓN, C. El territorio del Caquetá y la formación del estado en las fronteras difusas del Putumayo-Aguarico: precariedad y actores no convencionales (1845-1874). In: ETNOHISTORIA: miradas conectadas y renovadas. Quito: FLACSO. En prensa.

PÉREZ, R. La Compañía de Jesús en Colombia y Centro América después de su restauración. Valladolid: Imp., Lib., Heliografía y Taller de grabados de Luis N. de Gaviria, 1896-1898.

PINEDA CAMACHO, R. Holocausto en el Amazonas: una historia social de la Casa Arana. Bogotá: Planeta, 2000.

PORTELA GUARÍN, H. et al. Plan de Vida del Pueblo Siona Gantëya bain. Popayán: Editorial Universidad del Cauca, 2003. 
SANTA GERTRUDIS, J. de. Maravillas de la naturaleza: vols. I-IV. Bogotá: Biblioteca Banco Popular: Editorial Kelly, 1970.

SIMSON, A. Notes on the Piojes of the Putumayo. The Journal of the Anthropological Institute of Great Britain and Ireland, v. 8, p. 210-222, 1879.

TAUSSIG, M. Chamanismo, colonialismo y el hombre salvaje: un estudio sobre el terror y la curación. Bogotá: Grupo Editorial Norma, 2002.

TAYLOR, A. El Oriente ecuatoriano en el siglo XIX: el otro litoral. In: MAIGUSASHCA, J. Historia y Región en el Ecuador 1830-1930. Quito: Corporación Editora Nacional, 1994. p. 17-68.

TULCÁN, I. de. Memorias de la expedición por los ríos Guineo, Putumayo, Guamués, San Miguel y Aguarico. In: RECALDE, J. A. Misioneros capuchinos ecuatorianos. Cuenca: Impreso Editorial, 2002. p. 100-142.

TURNER, T. Ethno-ethnohistory: myth and history in native south American representations of contact with Western society. In: HILL, J. (ed.). Rethinking history and myth: indigenous South American perspectives on the past. Urbana: Illinois University Press, 1988. p. 235-281.

VILLAVA, A. de. Una visita al caquetá por un misionero capuchino. In: RECALDE, J. A. Misioneros capuchinos ecuatorianos. Cuenca: Impreso Editorial, 2002. p. 175-229.

WASSERSTROM, R. Surviving the rubber boom: Cofán and Siona society in the Colombia-Ecuador borderlands (1875-1955). Ethnohistory, v. 61, n. 3, p. 525-548, 2014.

WASSERSTROM, R.; REIDER, L.; ROMMEL, L. Nowbody knew their names: the black legend of Tetete extermination. Ethnohistory, v. 58, n. 3, p. 421-444, 2011.

WHEELER, A. Gantëya bain: el pueblo Siona: tomo 1. Bogotá: Editorial Townsend, 1987.

WHITE, H. The value of narrativity in the representation of reality. In: MITCHELL, W. J. T. On narrative. Chicago: The University of Chicago Press, 1981. p. 1-24.

Recebido: 30/09/2019 Aceito: 27/04/2020 | Received: 9/30/2019 Accepted: 4/27/2020

Esta obra está licenciada com uma Licença Creative Commons - Atribuição 4.0 Internacional This work is licensed under a Creative Commons Attribution 4.0 International License. 